\title{
Addressing Learner Satisfaction Outcomes in Electronic Instrumentation and Measurement Laboratory Course Organization
}

\author{
Sergio Gallardo, Federico J. Barrero, Senior Member, IEEE, M. Rocío Martínez-Torres, \\ Sergio L. Toral, Senior Member, IEEE, and Mario J. Durán
}

\begin{abstract}
This paper proposes and details a course organization methodology based on learner satisfaction achievement. The approach follows the prevailing tendency in modern university reforms which are primarily concerned about "how people learn." As a consequence, the learner has been placed as the main actor of the teaching-learning process. Nevertheless, the current learning literature has not addressed the measurement of learner satisfaction within laboratory and practical subjects. This study develops a general and comprehensive methodology for learner satisfaction measurement in practical subjects. As a case example, the proposed methodology has been applied to an electronic instrumentation and measurement course, confirming the variables with a significant influence on learner satisfaction and becoming the starting point for curriculum redesign based on the learner satisfaction approach. To assess the improvement of the proposed course organization methodology, a comparison with previous academic years has been performed showing the students' rated score evolution. Results fully confirm the validity of the technique and the novel course organization.
\end{abstract}

Index Terms-Course organization, educational technology, electronic engineering, electronic instrumentation and measurement lab, learner satisfaction.

\section{INTRODUCTION}

$\mathbf{T}$ HE notion of learner-centered education has been in existence since the early days of higher education institutions [1], [2]. Nevertheless, only recently has this concept reemerged because of reforms that are to be implemented in the year 2010 in the European countries (within European Higher Education) [3], [4]. New learning and teaching-centered patterns of the students have emerged as a result of these pedagogical reforms [5], [6].

In a teacher-centered model of instruction, the development of the instruction and control of the learning process is retained by the teacher. In this framework, some assume that the teacher needs to do things "to" and "for" the learner. In other words, the teacher manipulates the learning situation to obtain the desired outcomes guided by generalized characteristics of the learners
[7]. In this scenario, instruction is the activity which the information is moved or transmitted to and into the learner [8]. The teacher's role is to transfer knowledge to the students once it has been previously defined and organized from the teacher or expert's perspective. The teacher decides what is required for the learner from a perspective outside the learner, by defining characteristics of instruction, curriculum, assessment, and management [7], [9]. The teacher-centered methodology usually leads to rote learning and the stifling of critical and creative thinking [10]-[12].

In contrast, learner-centered practices move the focus from the teacher to the student, paying more attention to the learning performance rather than the instruction methodology. Instruction based on a learner-centered framework provides opportunities for learners to draw on their own experiences and interpretations of the learning process [7], [9], [13]. Learner-centered practices regard learning as a life-long process rather than as a process which takes place only through youth-adulthood. This occurs in the majority of current higher education reforms [14].

According to this second approach, learning is viewed as a natural and constructive process. Furthermore, if the learning is more meaningful and relevant to the student, the teaching efficiency is also increased. This learning ability is particularly important in courses with a high load of laboratory or practical work (where the skills and abilities of learners should improve), especially when the students get involved in the learning process assuming responsibility [15]. In order to accomplish the desired learning outcomes, teachers need to understand the learner's world and identify capacities already existing in the learner.

In this paper, a general procedure for evaluating learner satisfaction is described and used to design a course organization following a learner-centered approach. Section II describes the procedure and compares it with other existing methods for learner satisfaction measurement. The proposed methodology is applied in Section III to an electronic instrumentation and measurement course as a case example. The obtained results indicate the main variables with a significant influence on learner satisfaction, improving the understanding of the underlying learner satisfaction driving principles. According to these variables, a new course organization is proposed and applied to improve the most relevant dimensions previously highlighted. To estimate the improvement of the proposed course organization, a students' rated score evolution is showed. Finally, conclusions are drawn in Section IV. 


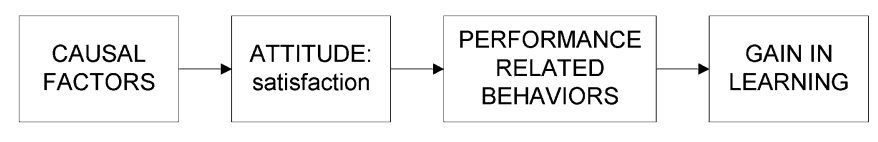

Fig. 1. Satisfaction as a central mediator of postlearning behavior.

\section{USER SATiSfaction MEASUREMENT}

Measurement issues are receiving increased attention among the education research community. The primary purpose for developing these measures is to predict behavior, and thus, the measurement of learner satisfaction should be more closely tied to the attitude-behavior theory.

Learner satisfaction is an important theoretical construct because of its potential for helping discover both forward and backward links in a causal chain that are important to the learning community [16]. Thus, learner satisfaction is potentially both a dependent variable (when the domain of one's research interest is upstream activities or factors that cause learner satisfaction) and an independent variable (when the domain is downstream behaviors affected by e-learner satisfaction).

Considerable research has been performed in social psychology about a person's attitudes and how these may affect behavior. Specifically, the Theory of Reasoned Action (TRA) [17] is a widely accepted model that has been used in predicting and explaining behavior across a wide variety of domains. TRA assumes that individuals behave rationally, and postulates that behavioral intention (and subsequently the final behavior) is a function of attitude (toward the behavior).

Based on this theoretical framework, satisfaction appraisal is generally considered the central mediator of postlearning behavior, which links preusage system beliefs to postusage cognitive structure, student communications, and reuse behavior (see Fig. 1). Most behavior researchers would agree that satisfaction influences future usage intention and complaining behavior. Students with high levels of satisfaction are expected to have higher levels of reuse intention and make less complaints [18].

Traditionally, the user satisfaction measurement has been used to assess information and management systems, including classroom teaching in traditional educational contexts [19]-[21]. This measurement cannot be evaluated using a single-dimension scale, such as global satisfaction, and it should incorporate different aspects of electronic-learner (e-learner) satisfaction to become a useful diagnosis instrument.

However, user satisfaction measurement developed for traditional educational contexts may no longer be appropriate for a laboratory or practical learning environment where the role of the learner is completely different to that of a student in a lecture-style setting. For instance, the way in which the educational material is delivered or the possibilities of feedback and interaction with physical instrumentation are quite different in a laboratory environment. Therefore, a need exists to develop a comprehensive instrument for measuring learner satisfaction within a practical or laboratory context [18].

Different dimensions must theoretically and operationally be defined to assess the extent and specific nature of learner satisfaction. According to [18], learner satisfaction is stimulated by several focal aspects, such as content, learner interface, learning community, and personalization. In [22], [23], an instrument for measuring end-user computing satisfaction was proposed. They developed an instrument that consisted of five dimensions: ease of use, content, accuracy, format, and timeliness. In some other studies new dimensions were added. For instance, assessment-centered instruction was highlighted in [24]. This dimension includes opportunities for both formative and summative assessment, allowing students to reflect on what they already know, to receive feedback, to try again after appropriate review, and to demonstrate their understanding of the material. Overall responsibility and user control were considered in [25] as a measurement of user participation and involvement. Finally, interactivity has also been claimed as an important dimension of user satisfaction [26], [27].

According to these above-mentioned studies, 10 dimensions have been considered: content, user interface, feedback, user control and interactivity, ease of use, enthusiasm and motivation, learning community, learner responsibility, previous experience, and satisfaction. A survey based on these dimensions has been applied to the course described in the next section.

\section{EleCtronic INSTRUMENTATION AND MEASUREMENT Lab: A CASE STUDY}

The course, "Electronic Instrumentation and Measurement Lab," is a 7.5-Spanish-credit (this is 75 hours since one Spanish credit is equal to ten hours of lessons) optional course at the Telecommunication Engineering school of the University of Seville, Seville, Spain. The Telecommunication Engineering degree comprises five academic years, and each year is divided into two semesters. The courses usually last one semester, and most of them consist of six credits on average. The analyzed lab course is placed in the second semester of the last year, and every year from 60 to 90 students enroll in the course.

The main goal of the course is to provide students with an understanding of the operation principles and applications of a selected range of elemental and advanced instruments, such as logic analyzers, oscilloscopes, spectrum analyzers, $L C R$ meters, etc., agreement with students skills through laboratory work experiences. The lab work is based on "hands on" instruction focusing on engineering topics, such as modulation techniques, microprocessors systems analysis, reflectometry principles, fixed telephone basics, instrumentation buses, etc. The students learn about instruments and lab equipment which are used while analyzing interesting electronic engineering systems and principles. Furthermore, other important abilities are improved in this course, such as collaborative work, and innovation and research skills.

The course is divided into two separated lab groups with 45 students per group. Group "A" takes place on Thursday, from 4:00 to 9:00 PM. Group "B" takes place on Friday, from 9:00 AM to 2:00 PM. The students must attend 12 lab sessions. Five hours per session are assigned to each group. The students are also divided into work groups of two or three people who work together during each lab session. Therefore, each student attends 12 five-hour sessions, working at 12 different work stations throughout the course. Each work station is composed of 
different electronic instruments and prototype boards that students have to use and test, respectively. The 12 lab sessions making up the course are organized as follows.

- Session 1: Design and analysis of elementary direct current (dc) meters and multimeters as measurement instruments.

- Session 2: Design and analysis of alternating current (ac) meters and multimeters. This lab work also includes the frequency response analysis of the meters and the implementation of elementary half/full bridge ac voltimeters.

- Session 3: Use of analog and digital oscilloscopes and their basic characteristics. This lab work includes the analysis of probes, their characteristics, performance, applications, and limitations.

- Session 4: Introduction to spectrum analyzers. This lab work is used to describe the operation principles of spectrum analyzers.

- Session 5: Measurement and characterization of passive impedances and filters using Wheatstone Bridges, $L C R$ and Spectrum Analyzers with tracking generators. The limitation of probes in high frequency applications is also studied to understand its influence on measurement errors.

- Session 6: Introduction to the use of logic analyzers and to the analysis of complex digital electronic and microprocessors systems, including systems and microcontroller interfacing.

- Session 7: Analysis of General Purpose Interface Buses (GPIB) and their application for controlling electronic equipment. GPIB protocol is used to implement virtual and remote instruments.

- Session 8: Analysis of complex analog electronic systems. The lab work is based on the study of audio principles, audio amplifiers classes and their characterization methods.

- Session 9: A detailed description of the electrical time domain reflectometry (ETDR) mechanism, its applications, and a method for interpreting ETDR signal waveforms are presented.

- Session 10: Introduction to basic telephony concepts and fundamentals. In this lab work, learners study line telephone communications principles and analyze a real telephone prototype.

- Session 11: Description of other digital modulation techniques like frequency modulation (FM) and frequency shift keying (FSK), and their applications. FM and FSK modulation techniques are analyzed both in time and frequency domains.

- Session 12: Analysis of advanced electronic digital systems (such as digital signal processors or DSP) and protocols (such as internal personal computers architecture) using logic analyzers.

Previous reading is required to understand the operation principles of the equipment and instruments to be used in each session. Before the beginning of the laboratory work, handbooks of the instruments and a detailed handout of each task are available to the students. No formal reports are required to evaluate the students' work, but the students have to answer on-lab questions during each laboratory session.

\section{A. User Satisfaction Assessment}

Items of Table I were distributed among the students enrolled in the Electronic Instrumentation and Measurement Lab course using a written questionnaire. This questionnaire consisted of 35 items which should be scored using a 1-7 Likert-type scale (1=strongly disagree, $7=$ strongly agree) [28]. All of these items are frequently reported in the literature [29], [30].

A Likert questionnaire was provided to each student at the end of every lab session. Therefore, every student has filled out one questionnaire per lab session (a total of 12 questionnaires per student), obtaining a total number of 1080 questionnaires. The percentage of responses left blank was not appreciable (less than $0.5 \%$ ).

Previous to the distribution of the questionnaires, their reliability was tested so that the proposed set of items always provided consistent and reliable responses, even if they were replaced with other similar items. Cronbach's alpha index (a reliability index associated with the variation accounted for by the true score of the "underlying dimension") was used. It shows how well a set of items measures a single latent dimension [31]. Table I shows the value of alpha (under the dimension between parenthesis) and the inter-item correlation associated with each item. This coefficient ranges from 0 to 1 . The higher the score is, the more reliable the generated scale. A value around 0.7 is an acceptable reliability coefficient, although lower thresholds are sometimes used in the literature [31]. The distributed questionnaire clearly achieves the mentioned condition for each dimension. Item-total correlation was also computed for each item. This value is associated with each item between parenthesis and shows the correlation of an item with the rest of the items used to measure the underlying dimension. This value has been used for scale refinement. As a result of this process, four items (not shown in Table I) were rejected, and 35 items were accepted.

One of the difficulties inherent in multivariable statistics is the problem of visualizing multidimensionality to understand the data set by considering the group of items together rather than focusing on just one item at a time. Fortunately, in data sets with many items, groups of items often move together. One reason for this grouping is that more than one item may measure the same driving principle, governing the behavior of the system. In many systems, only a few of such driving forces are present [32]. However, an abundance of instrumentation allows measurement of dozens of system items. Advantage can be taken from this redundancy of information, and the problem can be simplified by replacing a group of items with a single new one.

Principal components analysis is a quantitative and rigorous method for achieving this simplification [30]. The method generates a new set of items, called principal components. Each principal component is a linear combination of the original items. All the principal components are orthogonal to each other so that no redundant information is present. The principal components as a whole form an orthogonal basis for the data space.

The full set of principal components is as large as the original set of items. Nevertheless, the sum of the variances of the first 
TABLE I

VALIDATED SURVEY BASED ON LEARNER SATISFACTION DIMENSIONS

\begin{tabular}{|c|c|c|}
\hline $\begin{array}{l}\text { Dimension } \\
\text { (Reliability) }\end{array}$ & & Item (Correlation item-dimension) \\
\hline \multirow{5}{*}{$\begin{array}{l}\text { Content } \\
(0.8642)\end{array}$} & 1 & $\begin{array}{l}\text { The delivered material for the lab or practical work is useful for learning the } \\
\text { concepts related to this practical work. }(0.7452)\end{array}$ \\
\hline & 2 & The material needed for the lab work is clear and sufficient. $(0.7584)$ \\
\hline & 3 & $\begin{array}{l}\text { The delivered material for the lab or practical work is useful for learning the } \\
\text { concepts related to this practical work. }(0.7604)\end{array}$ \\
\hline & 4 & My understanding level after the practical work is good. (0.6632) \\
\hline & 5 & Practical work is based on real examples. (0.5099) \\
\hline \multirow{3}{*}{$\begin{array}{l}\text { User interface } \\
\quad(0.8068)\end{array}$} & 6 & $\begin{array}{l}\text { The available tools and resources for implementing the practical work are } \\
\text { appropriate for the successful implementation of the required work. }(0.6070)\end{array}$ \\
\hline & 7 & Learning necessities are covered by the practical work. (0.6799) \\
\hline & 8 & $\begin{array}{l}\text { Learning performance is improved because of the variety of equipment and } \\
\text { devices used during the required work. }(0.6732)\end{array}$ \\
\hline \multirow{3}{*}{$\begin{array}{l}\text { Feedback } \\
(0.6734)\end{array}$} & 9 & $\begin{array}{l}\text { Feedback information is useful to solve the difficulties found during the } \\
\text { implementation of the practical work. }(0.5484)\end{array}$ \\
\hline & 10 & $\begin{array}{l}\text { Students receive the necessary instructions during the accomplishment of the } \\
\text { practice. }(0.6842)\end{array}$ \\
\hline & 11 & The Teaching Staff is accessible and ready to solve the doubts that arise. (0.5851) \\
\hline \multirow{4}{*}{$\begin{array}{l}\text { User control } \\
\text { and } \\
\text { interactivity } \\
(0.8294)\end{array}$} & 12 & The practical work strengthens my interaction with the equipment. (0.6244) \\
\hline & 13 & $\begin{array}{l}\text { Students are free to use the equipment (related to the practice) that they consider } \\
\text { to be opportune. }(0.7389)\end{array}$ \\
\hline & 14 & $\begin{array}{l}\text { Students have got all the necessary reference material during the practical work. } \\
(0.5949)\end{array}$ \\
\hline & 15 & $\begin{array}{l}\text { Students are free to realize and to try different options during the accomplishment } \\
\text { of the practice. }(0.6658)\end{array}$ \\
\hline \multirow{5}{*}{$\begin{array}{l}\text { Ease of use } \\
\quad(0.8272)\end{array}$} & 16 & The practical work can be easily performed. (0.6684) \\
\hline & 17 & $\begin{array}{l}\text { The required knowledge for the practical work implementation is adapted to the } \\
\text { students' formative level. }(0.6948)\end{array}$ \\
\hline & 18 & The required material for the practical work implementation is reliable. $(0.5411)$ \\
\hline & 19 & The lab test station is easy to use. (0.6799) \\
\hline & 20 & Time supplied for implementing the practical work is appropriated. $(0.5345)$ \\
\hline \multirow{3}{*}{$\begin{array}{c}\text { Enthusiasm } \\
\text { and Motivation } \\
(0.8300)\end{array}$} & 21 & The motivation infused by the instructors to learn the material is high. $(0.5985)$ \\
\hline & 22 & I enjoy during the practical work implementation. $(0.7574)$ \\
\hline & 23 & The realization of the practical work is a motivating experience. $(0.7234)$ \\
\hline \multirow{2}{*}{$\begin{array}{l}\text { Learning } \\
\text { community } \\
(0.7134)\end{array}$} & 24 & $\begin{array}{l}\text { I am feeling a part of a project team during the realization of the practical work. } \\
(0.5544)\end{array}$ \\
\hline & 25 & I assume responsibilities in the assembly and test of the practice. $(0.5544)$ \\
\hline \multirow{2}{*}{$\begin{array}{l}\text { Learner } \\
\text { responsibility } \\
(0.6847)\end{array}$} & 26 & $\begin{array}{l}\text { I usually solve the difficulties arisen during the realization of the practice on my } \\
\text { own initiative. }(0.5206)\end{array}$ \\
\hline & 27 & My participation has contributed to the success of the practice. $(0.5206)$ \\
\hline \multirow{4}{*}{$\begin{array}{c}\text { Previous } \\
\text { experience } \\
(0.8134)\end{array}$} & 28 & $\begin{array}{l}\text { Compared to other lab course experiences, I enjoy myself more than in other lab } \\
\text { classes. }(0.6824)\end{array}$ \\
\hline & 29 & The practical work always improves my learning performance. $(0.7145)$ \\
\hline & 30 & $\begin{array}{l}\text { I usually overcome the difficulties during the accomplishment of the practice. } \\
(0.5571)\end{array}$ \\
\hline & 31 & The quality of the practical work performed in the past was high. (0.5895) \\
\hline \multirow{4}{*}{$\begin{array}{l}\text { Satisfaction } \\
(0.8424)\end{array}$} & 32 & $\begin{array}{l}\text { Overall, I consider the implementation of the practical work a positive experience } \\
\text { for improving my learning performance. }(0.6467)\end{array}$ \\
\hline & 33 & The available material for the practice is good. (0.6978) \\
\hline & 34 & The available equipment for the practice is good. (0.6930) \\
\hline & 35 & I am satisfied with the implementation of this practical work. (0.6701) \\
\hline
\end{tabular}

few principal components often exceed $60 \%$ of the total variance of the original data [32]. By examining these few new principal components-based (PCB) items, achieving a deeper understanding of the driving forces that generated the original data is possible.

When applying the principal component analysis to the set of collected data, reduction of the number of PCB items used to represent the dimensions is possible. The results of Table II show the explained variance by the first principal component of each dimension. The first principal component of each dimension is able to explain more than $60 \%$ of the total variability of this dimension.

Using the reduced set of data represented by each first principal component, the correlations of these first principal components with learner satisfaction can be evaluated. These correlations can be used to hypothesize the relationships among +dimensions, showing the ones with a significant influence in learner satisfaction. 
TABLE II

EXPLAINED VARIANCE BY THE FIRST PRINCIPAL COMPONENT OF EACH DIMENSION

\begin{tabular}{|c|c|}
\hline Dimension & $\begin{array}{c}\text { Explained variance } \\
\text { (per unit) }\end{array}$ \\
\hline Content (CON) & 0.7372 \\
\hline User Interface (UI) & 0.7201 \\
\hline Feedback (FED) & 0.6885 \\
\hline User control and interactivity (UCI) & 0.6608 \\
\hline Ease of use (EOU) & 0.5923 \\
\hline Enthusiasm and Motivation (EAM) & 0.7542 \\
\hline Learning community (LC) & 0.7782 \\
\hline Learner responsibility(LR) & 0.7612 \\
\hline Previous experience (PE) & 0.6559 \\
\hline Satisfaction (S) & 0.6802 \\
\hline
\end{tabular}

TABLE III

Correlations of First Principal Components of EACH Dimension

\begin{tabular}{|c|c|c|c|c|c|c|c|c|c|c|}
\cline { 2 - 11 } \multicolumn{1}{c|}{} & CON & UI & FED & UCI & EOU & EAM & LC & LR & PE & S \\
\hline CON & 1.00 & -0.68 & -0.64 & -0.58 & 0.75 & -0.64 & -0.49 & -0.53 & -0.47 & -0.67 \\
\hline UI & -0.68 & 1.00 & 0.58 & 0.64 & -0.67 & 0.67 & 0.47 & 0.49 & 0.61 & 0.75 \\
\hline FED & -0.64 & 0.58 & 1.00 & 0.54 & -0.65 & 0.62 & 0.43 & 0.45 & 0.51 & 0.56 \\
\hline UCI & -0.58 & 0.64 & 0.54 & 1.00 & -0.61 & 0.59 & 0.52 & 0.55 & 0.45 & 0.61 \\
\hline EOU & 0.75 & -0.67 & -0.65 & -0.61 & 1.00 & -0.73 & -0.47 & -0.52 & -0.56 & -0.77 \\
\hline EAM & -0.64 & 0.67 & 0.62 & 0.59 & -0.73 & 1.00 & 0.48 & 0.49 & 0.65 & 0.71 \\
\hline LC & -0.49 & 0.47 & 0.43 & 0.52 & -0.47 & 0.48 & 1.00 & 0.69 & 0.39 & 0.45 \\
\hline LR & -0.53 & 0.49 & 0.45 & 0.55 & -0.52 & 0.49 & 0.69 & 1.00 & 0.40 & 0.47 \\
\hline PE & -0.47 & 0.61 & 0.51 & 0.45 & -0.56 & 0.65 & 0.39 & 0.40 & 1.00 & 0.61 \\
\hline S & -0.67 & 0.75 & 0.56 & 0.61 & -0.77 & 0.71 & 0.45 & 0.47 & 0.61 & 1.00 \\
\hline
\end{tabular}

According to the results from Table III, the conclusion is that all the considered dimensions have a significant influence on learner satisfaction (whether a positive or a negative correlation, since principal component analysis is performing a linear transformation in the data space). The final model obtained is illustrated in Fig. 2. Worth mentioning are the four dimensions with a higher influence on the learning satisfaction: contentment, user interface, ease of use, and enthusiasm and motivation. These four dimensions are highlighted with bold lines in the model. The next three dimensions with a substantial influence on learner satisfaction are feedback, user control, and interactivity, and previous experience. All of them are correlated with learner satisfaction with a value greater than 0.5. Finally, learner community and learner responsibility are the dimensions with a lower influence on learner satisfaction (detailed in Fig. 2 with a dotted line).

\section{B. Improvements on the Current Course Organization in Accordance With Learner Satisfaction Measurements}

The results from the previous subsection illustrate those dimensions with a high influence on learner satisfaction which should be improved. For instance, topics related to content, user interface, ease of use, and enthusiasm and motivation should be promoted.

- The "content" dimension is improved, including new content related with novel technological applications. The new activities included in the lab are based on industrial buses and protocols, home automation systems, remote and virtual instrumentation control, or mobile technologies (Fig. 3) [33]-[35].

- The "user interface" dimension is improved using learning management systems (i.e., WebCT, Moodle, etc. [36]).

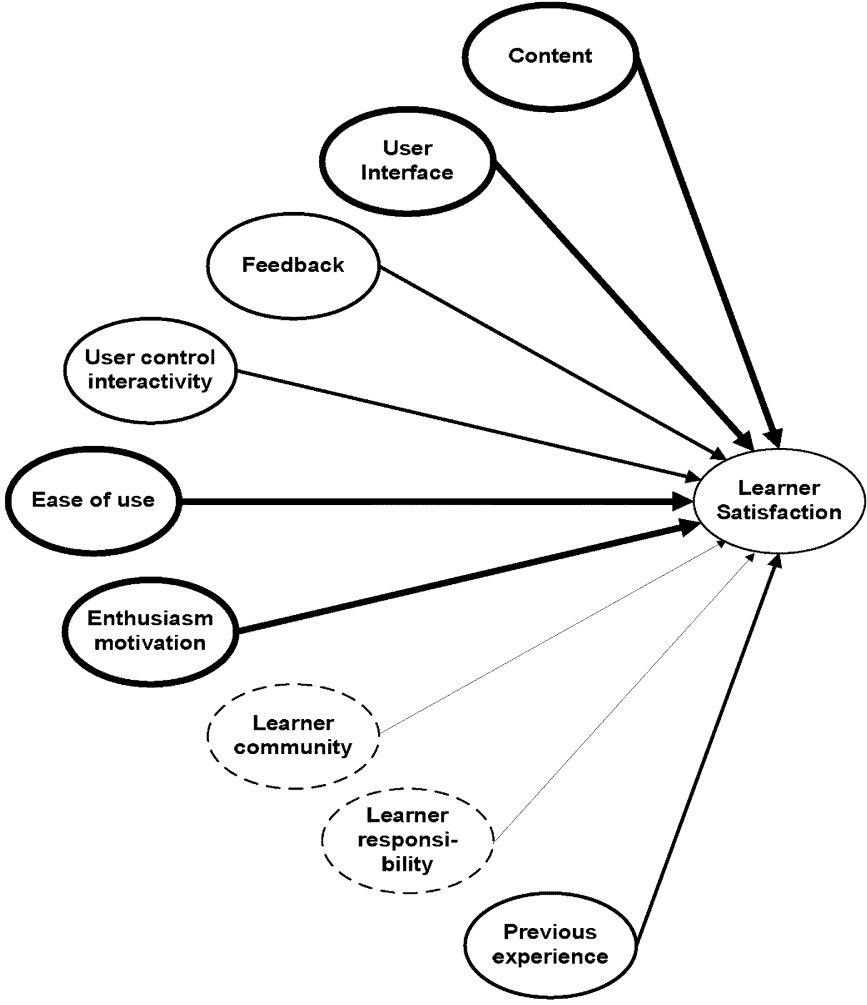

Fig. 2. Obtained model for learner satisfaction.

These systems, recently developed, make feasible a personalized user interface with complete control over instruction pacing and content management. The learning management system, based on Moodle, is a complete course management system (CMS)-open source software package- to produce Internet-based courses and Web sites. The remote environment opens the possibility to user authentication, students and teachers' accounts, resources such as forums, chats, etc. (Fig. 3). Furthermore, other courses could be included in the same system.

- The way in which the content is presented has also been taken into account to improve the "ease-of-use" dimension. Multimedia technologies and content have been developed to improve the learning processes (Fig. 3).

- Finally, the "enthusiasm and motivation" dimension could be improved if lab sessions surpass students' expectations. This improvement is obtained using real life applications, or even through rewards in the form of visible results of the lab work that can increase students' motivation and enthusiasm when working with practical implementations.

\section{Students' Rated Score Evolution During the Last Courses}

To validate the obtained results and to estimate the improvement that the proposed course organization methodology provides in the efficacy of the course, a comparison with previous academic years has been performed showing the students' rated score evolution (Figs. 4 and 5). To obtain this rated score, a range from -1 to 4 has been used, with -1 being "a student who has abandoned the course," 0 being "a student who has not passed the course," 1 being "a student who has passed the course," and 


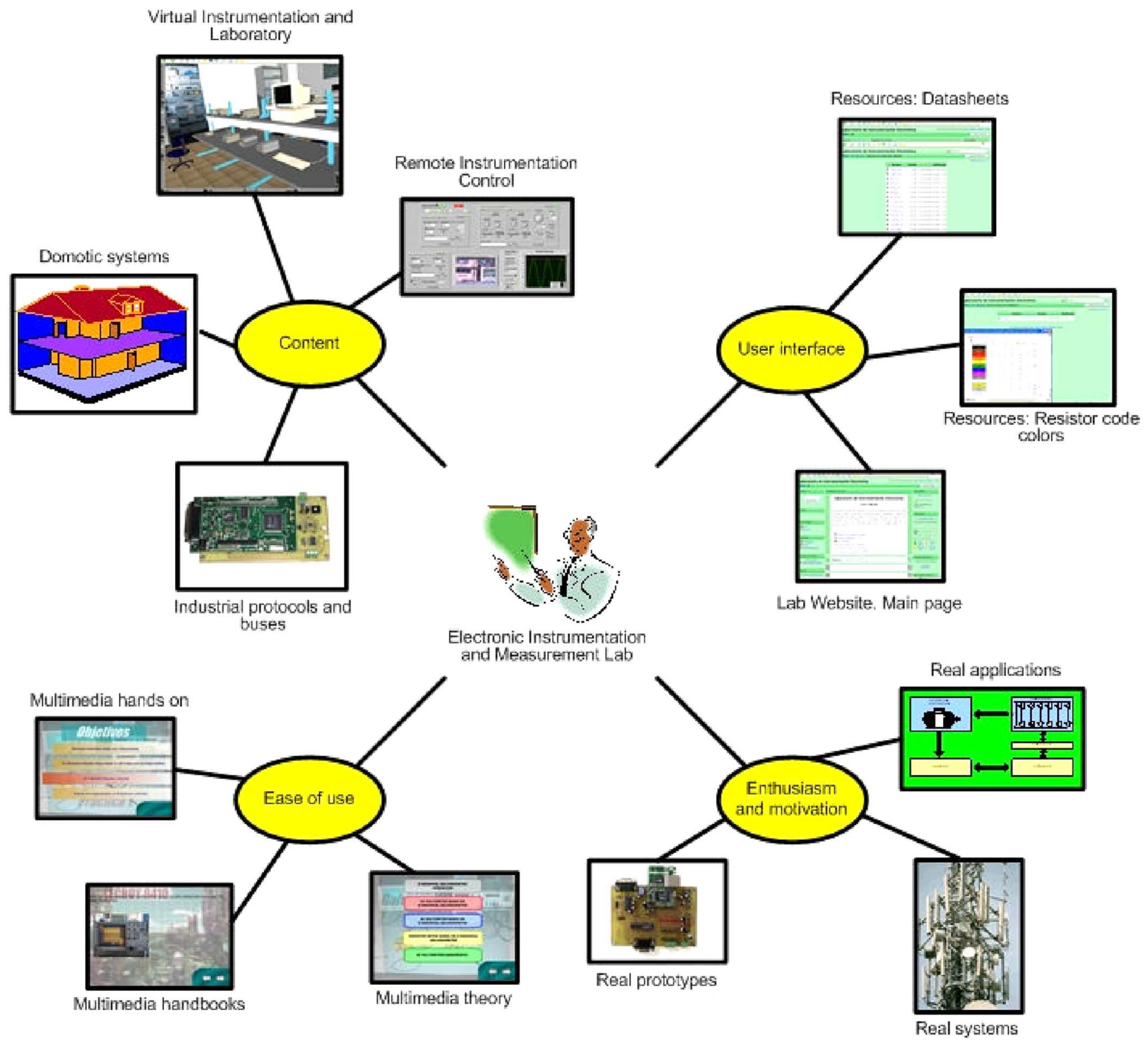

Fig. 3. Improvements on the current course organization according to learner satisfaction measures.

4 being "a student who has passed the course with honors." The numbers in between refer to intermediate scores. This scoring system penalizes the abandonment of the course by the students, one of the most important problems in Spanish Universities. The evaluation of the course depends fundamentally on the accomplishment of individual short written questionnaires about the developed lab work at each work station. The mark for each lab session has a contribution of $6 \%$ on the overall score $(72 \%$ in total). Some spontaneous questions are also presented to the work groups during the lab sessions which make up $28 \%$ of the overall score.

Fig. 4 shows the rated evolution of the students' scores during the last four academic courses. As can be observed in Fig. 4, the students' scores have improved during the 2005-2006 academic course. Ninety-four per cent of the students obtained a score of over 2 on the [ -1 to 4$]$ scale in contrast with the last courses with a maximum of $73 \%$ over 2 . The mean students' rated score evolution has also been considered to measure the effectiveness of the enhancements included in the course. Fig. 5 shows this evolution. As can be noted, the mean students' rated score has been improved by $14 \%$ ( 2.16 points) in comparison with the best result (academic course 2003-2004).

\section{CONCLUSION}

A scientific method for designing an Electronic Instrumentation and Measurement Lab course has been detailed. The adopted approach is based on learner satisfaction, according to the current European Higher Education reforms where the 


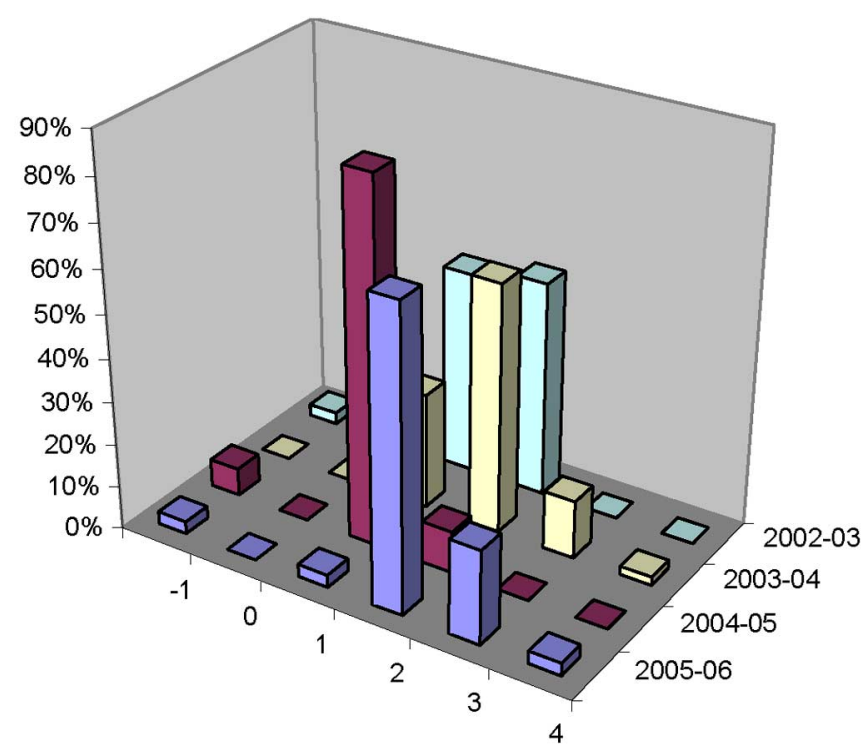

Fig. 4. Rated evolution of the students' scores in the [ -1 to 4$]$ scale during the last four years.

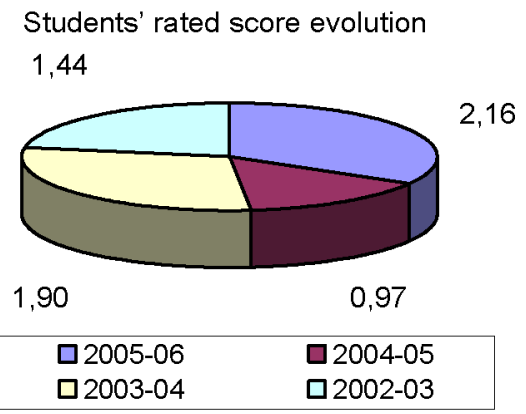

Fig. 5. Rated evolution of the students' scores during the last four years: mean value.

focus of attention is moved from teacher to learner which requires new teaching methodologies and learning environments. Learning environments are complex systems, and characterizing them using a single source of data may cause the teachers, evaluators, and researchers to misinterpret the learning processes. Students' perceptions of their classrooms normally provide an added and a better measure of a learner-centered process than teachers' perceptions.

In this study, student perceptions about several dimensions frequently referenced in the literature demonstrate how learnercentered principles can be used to improve a course organization. The dimensions with a higher influence on learner satisfaction are highlighted using principal component analysis, showing that content, user interface, ease of use, and motivation are the most appropriate ones to be reinforced. According to this analysis, the experimental course has been redesigned including new content and tools, such us multimedia technologies, realworld applications, or learning management systems. Postimplementation results are obtained, and a comparative analysis has been carried out showing the improvements on the students' evolution. The proposed methodology is general; it can be applied in any course; and the results demonstrate the usefulness of highlighting the relevant aspects to be improved from a learnercentered approach.

\section{REFERENCES}

[1] F. H. Hayward, The Educational Ideas of Pestalozzi and Froebal Ralph. London, U.K.: Holland, 1905.

[2] J. Dewey, The Child and the Curriculum and the School and Society. Chicago, IL: Univ. of Chicago Press, 1956.

[3] Commission of the European Communities (2005). Brussels, Nov. 10,2005 , Proposal for a recommendation of the European parliament and of the council on key competences for lifelong learning, $\operatorname{COM}(2005) 548$ final.

[4] Joint Declaration of the European Ministers of Education. Bologna, Jun. 19, 1999, The European Higher Education Area - Bologna Declaration.

[5] J. González and R. Wagenaar, Eds., Tuning Educational Structures in Europe Final Report Phase One. Bilbao/Groningen, Spain/Netherlands: Univ. of Deusto, Univ. of Groningen, 2003.

[6] J. González and R. Wagenaar, Eds., Tuning Educational Structures in Europe II: Universities' contribution to the Bologna Process. Bilbao/ Groningen, Spain/Netherlands: Univ. of Deusto, Univ. of Groningen, 2005.

[7] E. D. Wagner and B. L. McCombs, "Learner-centered psychological principles in practice: Designs for distance education," Educ. Technol. vol. 35, no. 2, pp. 32-35, 1995.

[8] D. Kember and L. Gow, "Orientations to teaching and their effect on the quality of student learning," J. Higher Educ., vol. 65, no. 1, pp. 58-74, 1994.

[9] K. L. Schuh, "Learner-centered principles in teacher-centered practices," Teaching Teacher Educ., vol. 20, pp. 833-846, 2004.

[10] P. M. Rowell, "Perspectives on pedagogy in teacher education: The case of Namibia," Int. J. Educational Develop., vol. 15, no. 1, pp. 3-13, 1995.

[11] T. Jessop and A. Penney, "A study of teacher voice and vision in the narratives of rural South African and Gambian primary school teachers," Int. J. Educational Develop., vol. 18, no. 5, pp. 393-403, 1998.

[12] M. O'Sullivan, "The reconceptualisation of learner-centered approaches: A Namibian case study," Int. J. Educational Develop., vol. 24, pp. 585-602, 2004.

[13] S. Hadjerrouit, "Learner-centered web-based instruction in software engineering," IEEE Trans. Educ., vol. 48, no. 1, pp. 99-104, Feb. 2005.

[14] S. L. Toral, M. R. Martínez-Torres, F. Barrero, S. Gallardo, E. Vargas, and V. Gónzalez, "Planning a master's level curriculum according to career space recommendations using concept mapping techniques," Int. J. Technol. Design Educ., to be published.

[15] N. M. Lambert and B. L. McCombs, , N. M. Lambert and B. L. McCombs, Eds., "Introduction: Learner-centered schools and classrooms as a direction for school reform," in How Students Learn: Reforming Schools Through Learner-Centered Education. Washington, DC: American Psychological Assoc., 1998, pp. 1-22.

[16] N. P. Melone, "A theoretical assessment of the user-satisfaction construct in information systems research," Manage. Sci., vol. 36, no. 1, pp. 76-91, 1990.

[17] Ajzen and M. Fishbein, Understanding Attitudes and Predicting Social Behavior. Englewood Cliffs, NJ: Prentice-Hall, 1980.

[18] Y.-S. Wang, "Assessment of learner satisfaction with asynchronous electronic learning systems," Inf. Manage., vol. 41, pp. 75-86, 2003.

[19] W. J. Doll, T. S. Raghunathan, J. U. L. Lim, and Y. P. Gupta, "A confirmatory factor analysis of the user information satisfaction instrument," Inf. Syst. Res., vol. 6, no. 2, pp. 177-189, 1995.

[20] R. McHaney, R. Hightower, and D. White, "EUCS test-retest reliability in representational model decision support systems," Inf. Manage., vol. 36, no. 2, pp. 109-119, 1999.

[21] R. McHaney, R. Hightower, and J. Pearson, "A validation of the enduser computing satisfaction instrument in Taiwan," Inf. Manage., vol. 39, no. 6, pp. 503-511, 2002.

[22] W. J. Doll and G. Torkzadeh, "The measurement of end-user computing satisfaction," MIS Quarterly, vol. 12, no. 2, pp. 259-274, 1988.

[23] W. J. Doll, W. Xia, and G. Torkzadeh, "A confirmatory factor analysis of the end-user computing satisfaction instrument," MIS Quarterly, vol. 18, no. 4, pp. 453-461, 1994.

[24] J. E. Greenberg, B. Delgutte, and M. L. Gray, "Hands-on learning in biomedical signal processing," IEEE Eng. Med. Biol. Mag., pp. 71-79, Jul./Aug. 2003 
[25] Bagchi, S. Kanungo, and S. Dasgupta, "Modeling use of enterprise resource planning systems: A path analytic study," Eur. J. Inf. Syst., vol. 12, pp. 142-158, 2003.

[26] M. Khalifa and R. Lam, "Web-based learning: Effects on learning process and outcome," IEEE Trans. Educ., vol. 45, no. 4, pp. 350-356, Nov. 2002.

[27] V. Kettanurak, K. Ramamurthy, and W. D. Haseman, "User attitude as a mediator of learning performance improvement in an interactive multimedia environment: An empirical investigation of the degree of interactivity and learning styles," Int. J. Human-Comput. Stud., vol. 54, pp. 541-583, 2001.

[28] R. Likert, "A technique for the measurement of attitudes," Arch. Psych., vol. 22, no. 140, pp. 1-55, Jun. 1932.

[29] M. R. Martínez-Torres, F. Barrero, S. L. Toral, and S. Gallardo, "A digital signal processing teaching methodology using concept-mapping techniques," IEEE Trans. Educ., vol. 48, no. 3, pp. 422-429, Aug. 2005.

[30] S. L. Toral, F. Barrero, M. R. Martínez-Torres, S. Gallardo, and J. Lillo, "Implementation of a web-based educational tool for digital signal processing teaching using the technological acceptance model," IEEE Trans. Educ., vol. 48, no. 4, pp. 632-641, Dec. 2005.

[31] W. W. Chin, , G. A. Marcoulides, Ed., The Partial Least Squares Approach for Structural Equation Modeling. Mahwah, NJ: Erlbaum, 1998, pp. 295-336, Modern methods for business research.

[32] A. C. Rencher, Methods of Multivariate Analysis, Wiley Series in Probability and Statistics, 2nd ed. New York: Wiley, 2002.

[33] F. J. Cortés, S. Gallardo, F. Barrero, and S. L. Toral, "Using a home-domotic prototype based on CAN, GPRS and Ethernet interfaces for virtual monitoring applications: A case study in an undergraduate instrumentation course," in Proc. Int. Conf. Engineering Education, Madrid, Spain, Nov. 2005, pp. 1-6.

[34] S. Gallardo, F. Barrero, and S. L. Toral, "Building a web-based virtual laboratory with VRML. A case study: A electronic instrumentation subject," in Proc. Int. Conf. Engineering Education, Madrid, Spain, Nov. 2005, pp. 1-5.

[35] S. Gallardo, F. Barrero, and S. L. Toral, "Virtual instrumentation laboratory based on Labview. A case study: A DSP course," in Proc. Int. Conf. Engineering Education, Madrid, Spain, Nov. 2005, pp. 1-6.

[36] E. W. T. Ngai, J. K. L. Poon, and Y. H. C. Chan, "Empirical examination of the adoption of WebCT using TAM," Comput. Educ., vol. 48, pp. 250-267, 2007.

Sergio Gallardo was born in Huelva, Spain, in 1978. He received the M.Sc. degree in telecommunication engineering from the University of Seville, Seville, Spain, in 2002 and is currently pursuing the Ph.D. degree in information and communication technologies.

In 2002, he joined the Electronic Engineering Department at the University of Seville, where he is currently an Assistant Professor. His current interests include microprocessor and DSP devices systems, information and communication technologies, and virtual-remote instrumentation.
Federico J. Barrero (M'04-SM'05) was born in Seville, Spain, in 1967. He received the M.Sc. and Ph.D. degrees in electrical engineering from the University Seville, Seville, Spain, in 1992 and 1998, respectively.

In 1992, he joined the Electronic Engineering Department at the University of Seville, where he is currently a Full Professor. His recent interests include microprocessor and DSP devices systems, control of electrical drives and power electronics, and information and communication technologies systems applied to educational environments.

M. Rocío Martínez-Torres was born in Madrid, Spain, in 1973. She received the M.Sc. and Ph.D. degrees from the University of Seville, Seville, Spain, in 1996 and 2003, respectively.

She is currently a Full Professor in the Business Administration and Marketing Department at the University of Seville. Her research interests include intellectual capital and knowledge management.

Sergio L. Toral (M'01-SM'06) was born in Rabat, Morocco, in 1972. He received the M.Sc. and Ph.D. degrees in electrical engineering from the University of Seville, Seville, Spain, in 1995 and 1999, respectively.

$\mathrm{He}$ is currently a Full Professor in the Electronic Engineering Department at the University of Seville. His research interests include microprocessor and DSP devices systems, stochastic processing and their industrial applications, and information and communication technologies systems applied to educational environments.

Mario J. Durán was born in Malaga, Spain, in 1975. He received the M.Sc. and $\mathrm{Ph} . \mathrm{D}$. degrees in electrical engineering from the University of Malaga, Malaga, Spain, in 1999 and 2003, respectively.

$\mathrm{He}$ is currently an Assistant Professor in the Electrical Engineering Department at the University of Seville, Seville, Spain. His research interests include variable speed drives, multiphase machines and VSC modeling, and information and communication technologies systems applied to educational environments. 